\title{
Evaluasi Tata Kelola Keamanan Sistem Informasi Menggunakan Framework Cobit 5 Pada PT. Tsabita Cake
}

\author{
Azifa Habiba**1, Yonathan Aditya Saputra ${ }^{2}$, Aris Puji Widodo ${ }^{3}$ \\ Magister Sistem Informasi, Sekolah Pascasarjana, Universitas Diponegoro \\ Jalan Prof. Soedarto, SH Tembalang Semarang \\ azifahabiba@students.undip.ac.id, yonathanadhit@students.undip.ac.id,, \\ arispw@lecturer.undip.ac.id, kusworo@lecturer.undip.ac.id
}

\begin{abstract}
Abstrak
Penelitian ini dilakukan dengan tujuan mengevaluasi kematangan tata kelola teknologi informasi (TI) berada pada level berapa dalam penerapan layanan sistem informasi pada PT. Tsabita Cake. Dalam penelitian ini menggunakan metode kuantitatif dan kualitatif dengan beberapa tahapan mulai dari kuesioner, wawancara, dan studi dokumen. Penelitian terfokus pada Domain DSS 05. Hasil yang didapat dari penelitian ini dibutuhkan sebagai sebuah evaluasi dan masukan untuk perbaikan terhadap tata kelola sistem informasi PT. TSABITA CAKE dimasa yang akan datang. Setelah dilakukan penelitian memperoleh hasil akhir yang menunjukkan tingkat kematangan tata kelola TI pada layanan Sistem Informasi PT. TSABITA CAKE saat ini berada pada kapabilitas sebesar 75\% atau setara dengan 2.90 dengan status largely achieved dan berada pada level 2. Maka dari itu keamanan sistem informasi perlu ditingkatkan untuk mendukung kinerja PT. TSABITA CAKE agar bisa mencapai level 3 diperlukan rekomendasi perbaikan terhadap proses penilaian dari level 1 sampai level 3. Untuk rencana pengembangan pada tata kelola TI diharapkan agar lembaga menyiapkan SDM yang unggul, serta mengarsipkan setiap kegiatan evaluasi dan monitoring pada pengelolaan sistem informasi..
\end{abstract}

Kata kunci: Tata Kelola, COBIT 5, Monitor dan evaluasi, Sistem Informasi, bisnis

\begin{abstract}
This research was conducted with the aim of evaluating the maturity of information technology (IT) governance at what level in the application of information system services at PT. Tsabita Cake. In this study, using quantitative and qualitative methods with several stages starting from questionnaires, interviews, and document study. This research focuses on the DSS Domain 05. The results obtained from this study are needed as an evaluation and input for improvement of the information system governance of PT. TSABITA CAKE in the future. After doing the research, get the final result that shows the maturity level of IT governance in the Information System services of PT. TSABITA CAKE is currently at a capability of $75 \%$ or equivalent to 2.90 with the status largely achieved and at level 2. Therefore, information system security needs to be improved to support the performance of PT. TSABITA CAKE in order to reach level 3 requires recommendations for improvement of the assessment process from level 1 to level 3. For the development plan on IT governance, it is hoped that the institution will prepare superior human resources, and archive every evaluation and monitoring activity in information system management.
\end{abstract}

Keywords: Governance, COBIT 5, Monitor and evaluation, Information System, business 


\section{PENDAHULUAN}

$\mathbf{P}$ enerapan Teknologi Informasi telah menjadi unsur penting karena daya efektifitas dan efisiensi yang mampu mempercepat kinerja sehingga dapat mendorong keunggulan bersaing baik secara finansial maupun jaringan [3]. Penerapan Tata kelola TI dapat memudahkan kegiatan evaluasi dan monitoring sebuah sestem informasi. Saat ini di berbagai lini kehidupan dituntut untuk menggunakan Teknologi informasi (TI) sehingga mendorong seluruh instansi untuk memanfaatkan teknologi informasi dalam menjalankan peran organisasinya. Begitu juga perkembangan teknologi informasi dibidang industri.

Penerapan evaluasi dan monitoring secara berkala dapat meningkatkan kualitas layanan bagi pelaku bisnis. Penerapan tata kelola ini harus diimbangi dengan implementasi sesuai dengan perangkat yang dimiliki oleh sebuah perusahaan. Metode untuk melakukan evaluasi tata kelola TI ada beberapa, misalnya framework ISO 27000, ITIL V.3, framework COBIT [2]. COBIT adalah tool yang sering digunakan dalam proses evaluasi tata kelola sistem informasi. Pada Framework tersebut terdapat ukuran, indikator untuk membantu pengoptimalan dari pengelolan teknologi informasi dan memberikan kendali terhadap penggunaan teknologi informasi yang tepat untuk sebuah organisasi. Tujuannya adalah agar organisasi tersebut merasa bahwa teknologi informasi yang mereka investasikan memberikan dampak positif bagi perusahaan mereka.

Penerapan Sistem informasi sudah mulai diterapkan pada banyak perusahaan meskipun pada pemanfaatannya masih dirasa belum maksimal. Faktor yang menentukan tingkat pemanfaatan ini yaitu isi dari informasi, akses yang mudah dan ketersedian sistem yang belum sesuai dengan keinginan penggunanya. Dari beberapa kasus tersebut maka sangat penting untuk melakukan evaluasi. Evaluasi digunakan untuk mengetahui apakah sistem informasi yang ada masih layak diterapkan atau perlu dilakukan pengembangan sistem melalui hasil evaluasi. Pemenuhan evaluasi framework COBIT 5 dapat menggunakan domain DSS 05 (Deliver, Service, dan Support) yang berfokus pada keamanan sistem informasi.

PT Tsabita Cake \& Bakery merupakan perusahaan pembuatan roti berlokasi di Soloyang dirintis dari tahun 2006. Tantangan berat pada toko roti tersebut menurut pemiliknya yaitu dari sisi sumber daya manusia, bagaimana memberikan pemahaman kepada mereka tentang pabrik roti tersebut yang bermula dari home industry dengan berbagai kelonggarannya menuju sumber daya manusia yang lebih baik dalam sebuah perusahaan yang tertib, disiplin, terjaga produktivitas kerjanya. PT Tsabita Cake \& Bakery berawal dari usaha rumahan yang didirikan di depan teras rumah kontrakan yang akhirnya sekarang memiliki ratusan karyawan dan pabrik yang tersistem secara rapi. Dari awal berdiri hingga 2015 masih menggunakan sistem yang serba manual hingga pada akhirnya di tahun 2015 mulai melakukan transformasi menggunakan sistem komputasi yang bagus pada sebuah sistem informasi.

Akan tetapi pihak instansi belum melakukan pengukuran sejauh mana investasi teknologi informasi akademik ini meningkatkan efisiensi. Untuk itu perlu dilakukan sebuah pengukuran melalui "Evaluasi Tata Kelola Menggunakan COBIT 5 domain DSS 05 pada PT. TSABITA CAKE" sebagai acuan ketika melakukan perencanaan pengembangan sebuah sistem dengan tujuan agar dapat mengetahui seberapa jauh pemanfaatan sistem informasi yang ada dan ada pada level berapa tingkat kematangan sistem informasi yang sudah berjalan. 


\section{LANDASAN TEORI}

\subsection{Tata Kelola Teknologi Informasi}

\subsubsection{Definisi Tata Kelola Teknologi Informasi}

IT governance merupakan bagian dari pengelolaan perusahaan secara keseluruhan, meliputi pimpinan, struktur organisasi dan proses, yang digunakan untuk memastikan keberlajutan TI dalam organisasi dan pengembangan tujuan dan strategi organisasi [4].

"Specifying the decision rights and accountability framework to encourage desirable behavior in using IT" merupakan sebuah kutipan pada jurnal yang mendefinisikan bahwa IT Governance adalah framework yang spesifik untuk melakukan pengambilan keputusan dan akuntabilitas untuk mendukung kebiasaan perusahaan dalam menggunakan teknologi informasi [1]. Terdapat beragam definisi mengenai pengertian IT Governance, akan tetapi dari semua definisi yang ada selalu berfokus pada 5 hal yang berkaitan dengan:

a. Akuntabilitas teknologi informasi,

b. Kepatuhan terhadap peraturan dan ketentuan teknologi informasi,

c. Memuaskan kebutuhan dewan dan pemangku kepentingan,

d. Manajemen risiko, dan

e. Memberikan nilai bagi bisnis dan kontrol dari kerja yang dilakukan.

\subsubsection{Pentingnya Tata Kelola Teknologi Informasi}

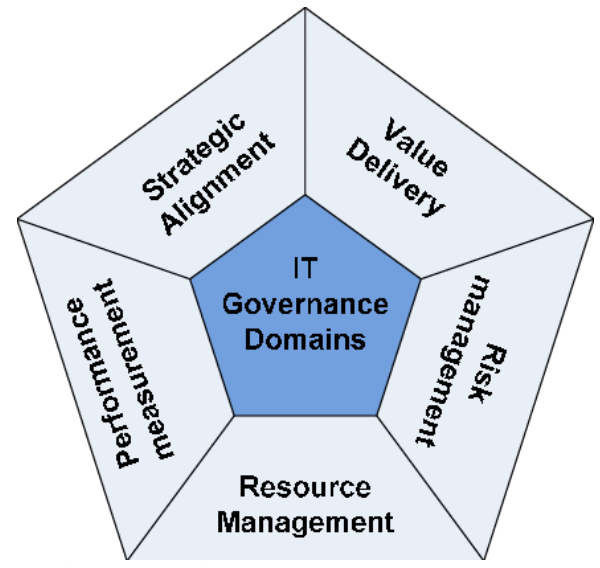

Gambar 1. Fokus Area IT Governance [6]

Fokus area tata kelola teknologi pada Gambar 2.1 dapat dijelaskan sebagai berikut:

a. Strateggic Aligment: Memastikan proses bisnis dengan rencana teknologi informasi, maintenance dan melakukan uji validasi usulan nilai teknologi informasi, serta menyeimbangkan tujuan bisnis dan tujuan teknologi informasi.

b. Value delivery: Menjalankan proposisi nilai seluruh siklus delivery, memastikan bahwa teknologi informasi memberi dampak positif sesuai dengan tujuan bisnis yang diarsipkan dalam strategi, berfokus terhadap biaya pengoptimalan.

c. Resource management: Upaya investasi yang maksimal dalam mengelola sumber daya teknologi informasi seperti aplikasi, informasi, infrastruktur dan SDM dan pengoptimalisasian infrastruktur.

d. Risk management: Menjelaskan mengenai kesadaran dalam mengelola risiko oleh stakeholder pada satu instansi, lalu memahami prosedur prosedur tata kelola teknologi informasi, terbuka terhadap resiko - resiko yang ada pada perusahaan dan melakukan tanggung jawab atau bentuk penyelesaia manajemen risiko ke dalam organisasi [10].

Habiba, et., al [Evaluasi Tata Kelola Keamanan Sistem Informasi Menggunakan Framework Cobit 5 pada 
e. Performance measurement: Mengukur seberapa efektifnya kinerja dan penerapan pada strategi, penyelesaian proyek, kepatuhan sumber daya, keseimbangan antara kinerja proses dan pelayanan seperti balanced scorecard yang menerjemahkan strategi ke dalam tindakan untuk mencapai tujuan yang terukur.

\subsubsection{COBIT 5}

COBIT 5 adalah produk terbaru dari COBIT yang dikembangkan lebih dari 25 tahun oleh ISACA. COBIT 5 merupakan framework yang berupa panduan best practice dengan menyajikan kegiatan Tata kelola TI dengan focus pada kontrol bukan pada eksekusi. Framework ini dapat membantu memastikan penyampaian layanan dan memberikan pengukuran penilaian pada sistem [5].

COBIT terdiri dari tata kelola dan manajemen TI yang berkembang secara luas sehingga dapat digunakan dalam tata kelola TI dengan tujuan yang dikelompokkan dalam 2 area kerja yaitu Governance yang didalamnya ada 1 domain yaitu Evaluate, Direct, and Monitor (EDM) dan Management memiliki 4 domain yaitu Align, Plan, and Organise (APO), Build, Acquire, and Implement (BAI), Deliver, Service, and Support (DSS), Monitor, Evaluate, and Assess (MEA).Evaluate, Direct, and Monitor (EDM), Align, Plan, and Organize (APO), Build, Acquire, and Implement, (Deliver, Service, and Support dan Monitor, Evaluate, and Assess (MEA) [7].

\section{METODOLOGI PENELITIAN}

\subsection{Jenis, Sifat dan Pendekatan Penelitian}

Pendekatan kuantitatif dan kualitatif yang diterapkan pada penelitian ini, menggunakan model matematis serta proses pengukuran pada satu kejadian dan hubungannya [8]. Sedangkan pedekatan kualitatif adalah pendekatan berdasarkan kejadian alamiah pada PSI PT. Tsabita Cake.

\subsection{Alur Penelitian}

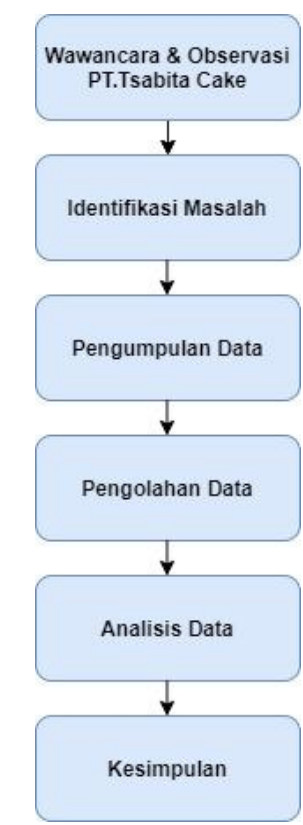

Gambar 2. Alur Penelitian 
a. Wawancara

Wawancara dilakukan kepada karyawan yang berkaitan dengan Sistem Informasi PT. Tsabita Cake. Hasil wawancara tersebut digunakan sebagai pertimbangan dalam memilih domain yang akan digunakan dengan Framework COBIT 5.

b. Observasi

Dalam tahap ini peneliti melakukan pengumpulan data terkait Sistem Informasi PT. Tsabita Cake. Hasil observasi digunakan sebagai penambah data dalam menunjang pemilihan domain pada Framework COBIT 5.

c. Identifikasi Masalah

Pada tahap ini peneliti mengidentifikasi masalah yang ada pada Tsabita Cake sebagai dasar untuk penyelesaian masalah dengan menggunakan Framework COBIT 5 sebagai proses auditnya.

d. Pengumpulan Data

Pada tahap ini, setelah didapatkan hasil dari wawancara awal hingga tahap identifikasi masalah, yaitu membuat kuesioner. Kuesioner disusun menggunakan standar COBIT 5, domain yang akan digunakan adalah domain DSS 05 yang kemudian kuesioner tersebut disebarkan ke responden. Responden kuesioner ditentukan berdasarkan RACI Chart.

e. Pengolahan Data

Tahap ini merupakan tahap yang terpenting dalam penelitian, karena untuk mengetahui nilai tingkat kematangan dan informasi tentang sikap pengguna terhadap tata kelola TI di PT. Tsabita Cake.

f. Analisis Data

Analisa data dilakukan terhadap pernyataan kuesioner dengan menggunakan model kapabilitas sebagai alat ukur terhadap jawaban responden dari kuesioner yang dibuat berdasarkan framework COBIT 5. Hasil dari perhitungan akan dilakukan analisis kesenjangan. Analisis data yang dilakukan terdiri dari analisis kapabilitas saat ini, tingkat kapabilitas yang diharapkan, dan analisis kesenjangan (gap analysis). Setelah mendapatkan nilai kapabilitas dari hasil kuesioner yang sudah disebarkan sebelumnya dan dianalisis setiap proses atributnya (PA) dengan mendapatkan kriteria penilaian 1-4. Pada setiap proses atribut dijumlah, kemudian hasilnya akan dirata-rata dan dibagi sesuai dengan bobot dan dikalikan 100\%. Dengan melihat hasilnya, maka dapat diketahui kondisi tata kelola TI di Tsabita Cake dan mendapatkan hasil akhir serta dikategorikan menurut Capability Level berikut (Tabel 2):

Tabel 1. Proses Capability Levels

\begin{tabular}{ccc}
\hline \hline Scale & Description & Rating \\
\hline $1(\mathrm{~N})$ & Not Achieved & $0 \%-15 \%$ \\
\hline $2(\mathrm{P})$ & $\begin{array}{c}\text { Partially } \\
\text { Achieved }\end{array}$ & $15,1 \%-50 \%$ \\
& $\begin{array}{c}\text { Largely } \\
\text { Achieved }\end{array}$ & $50,1 \%-85 \%$ \\
\hline $3(\mathrm{~L})$ & Fully Achieved & $85,1 \%-100 \%$ \\
\hline $4(\mathrm{~F})$ &
\end{tabular}

g. Kesimpulan

Berisi rangkuman yang didapatkan dari pembahasan. 


\section{HASIL DAN PEMBAHASAN}

Berdasarkan masalah dan tujuan penelitian yang sudah dipaparkan pada pendahuluan dan tahap-tahap penelitian pada metode peneletian, maka penelitian akan berfokus pada pokok permasalahan yang berkaitan dengan tujuan penelitian. Tahapan penelitian ini yaitu mengidentifikasi, menganalisa serta mengevaluasi keamanan sistem informasi PT. Tsabita Cake. Hasil yang diperoleh nanti akan digunakan untuk pembuatan strategi perbaikan agar diperoleh hasil yang maksimal sesuai tujuan dari organisasi, hal tersebut dilakukan agar nilai yang dibutuhkan dapat diperoleh dengan melakukan beberapa tahap, yaitu:

1. Hasil Studi Dokumen

Studi dokumen dilakukan untuk mendapatkan refernsi teori tentang permasalahan yang terjadi pada PT. Tsabita Cake. Penelitian ini dilakukan untuk mengukur Capability Level dari keamanan sistem informasi yang relevan dengan menggunakan panduan kerja COBIT 5. Selain itu juga mempelajari dokumen penelitian-penelitian sebelumnya yang digunakan sebagai referensi dalam mencari solusi permasalahan yang ada pada PT. Tsabita Cake.

2. Hasil Wawancara

Wawancara dilakukan untuk mendapatkan informasi yang didapatkan dari Kepala Bagian IT, wawancara dilakukan disesuaikan dengan sub domain DSS05 mengenai keamanan sistem informasi. Hasil wawancara dapat dilihat pada Tabel 3 sesuai dengan sub domain DSS05.

Tabel 2. Hasil Wawancara

\begin{tabular}{|c|c|}
\hline $\begin{array}{l}\text { Pertanyaan Wawancara } \\
\text { Sesuai DSS05 }\end{array}$ & Hasil \\
\hline $\begin{array}{l}\text { DSS05.01 } \\
\text { Protecs Again Malware }\end{array}$ & $\begin{array}{l}\text { Website antivirus yang digunakan adalah SSL, dan untuk } \\
\text { komputer internal masih menggunakan windows defender } \\
\text { karena terus melakukan update dan free akan tetapi setiap user } \\
\text { komputer dapat menambahkan antivirus, dan ditambahkan } \\
\text { settingan terhadap jaringan luar agar tidak bisa mengakses } \\
\text { komputer internal }\end{array}$ \\
\hline $\begin{array}{l}\text { DSS05.02 } \\
\text { Manage Network and } \\
\text { Connectivity Security }\end{array}$ & $\begin{array}{l}\text { Untuk melakukan akses terhadap jaringan dibagi menjadi } 2 \text {, } \\
\text { publik dan internal, jaringan publik bersifat free access dan } \\
\text { jaringan internal hanya digunakan oleh pihak internal setiap user } \\
\text { perbidang. }\end{array}$ \\
\hline $\begin{array}{l}\text { DSS05.03 } \\
\text { Manage Endpoint Security }\end{array}$ & $\begin{array}{l}\text { Setiap komputer diberikan antivirus dan akses password } \\
\text { masing-masing, akan tetapi ada beberapa komputer yang } \\
\text { bersifat free access }\end{array}$ \\
\hline $\begin{array}{l}\text { DSS05.04 } \\
\text { Manage User Identify and } \\
\text { Logical Access }\end{array}$ & $\begin{array}{l}\text { Pembagian hak akses terhadap sistem ataupun komputer dengan } \\
\text { menyesuaikan tanggungjawab dan wewenang setiap user. }\end{array}$ \\
\hline $\begin{array}{l}\text { DSS05.05 } \\
\text { Manage Physical Access } \\
\text { to IT Assets }\end{array}$ & $\begin{array}{l}\text { Ruangan server sudah memiliki tempat dan hanya user terntentu } \\
\text { yang memiliki tanggung jawab dan wewenang untuk masuk } \\
\text { ruang server }\end{array}$ \\
\hline $\begin{array}{l}\text { DSS05.06 } \\
\text { Manage Sensitive } \\
\text { Documents and Outputs } \\
\text { Device }\end{array}$ & $\begin{array}{l}\text { Penyimpanan dokumen secara fisik disimpan pada ruangan } \\
\text { arsip, sedangkan untuk dokumen yang bersifat soft copy akan } \\
\text { diback up secara rutin dan ditempatkan ke beberata tempat }\end{array}$ \\
\hline $\begin{array}{l}\text { DSS05.07 } \\
\text { Monitor the Infrastructure } \\
\text { for Security Related }\end{array}$ & $\begin{array}{l}\text { Jika terdapat gangguan pada server ataupun jaringan akan selalu } \\
\text { dilaporkan kemudian dilakukan pengecekan untuk mengetahui } \\
\text { bidang mana yang mengalami gangguan }\end{array}$ \\
\hline
\end{tabular}

Habiba, et., al [Evaluasi Tata Kelola Keamanan Sistem Informasi Menggunakan Framework Cobit 5 pada PT. Tsabita Cake 


\section{Hasil Kuesioner}

Hasil kuesioner didapatkan dari perhitungan kuesioner yang diberikan terhadap responden PT. Tsabita Cake yang dirangkum dalam tabel dan dikelompokkan sesuai level dan diberi penilaian pada setiap atributnya. Hasil kuesioner tersebut dapat dilihat pada Tabel 4.

Tabel 3. Hasil Kuesioner

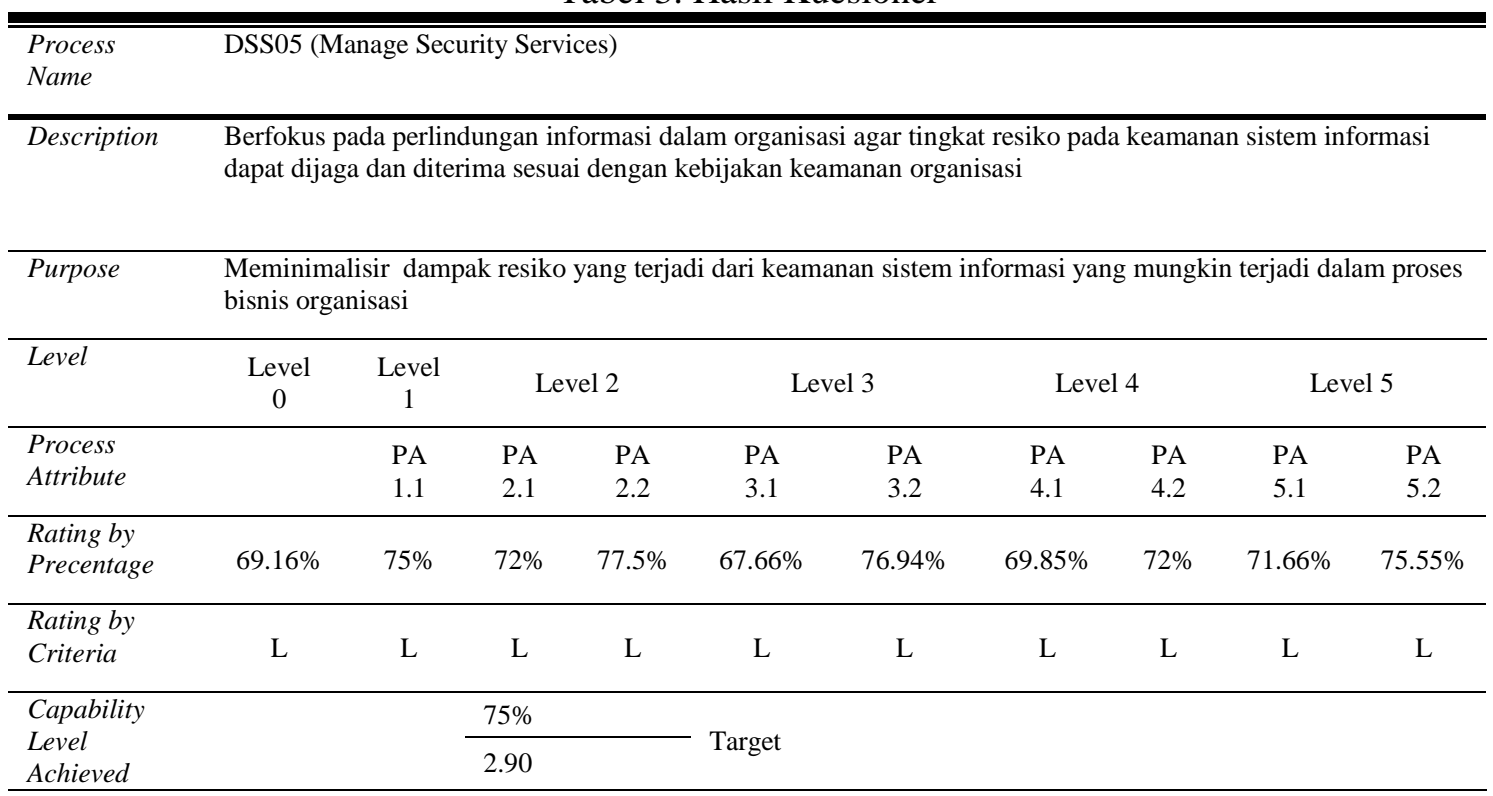

Dari hasil perhitungan Tabel 4 Capability Level kuesioner diatas, level yang sudah dicapai oleh Tsabita Cake terkait dengan keamanan teknologi informasi saat ini sudah berada pada level 2 yaitu managed process dengan hasil rata-rata yang didapatkan sebesar $75 \%$ dan memiliki status Larged Achieved (L) atau setara dengan 2.90. Hal tersebut dapat dinyatakan bahwa proses pengelolaan keamanan sistem informasi Tsabita Cake sudah dilakukan cukup baik akan tetapi belum ada proses perbaikan, penyesuaian dan perencanaan menuju kearah yang lebih baik. Dari hasil Capability Level dapat disimpulkan bahwa kondisi saat ini Tsabita Cake dalam melindungi teknologi informasi dari malware menggunakan antivirus pada sistem operasi windows akan tetapi belum diterapkan kewajiban menggunakan antivirus tambahan pada setiap user, konektivitas jaringan internet masih terdapat gangguan seperti susah sinyal dan terputus dari jaringan.. Sedangkan standar keamanan sistem informasi PT. Tsabita Cake sudah ditetapkan, yaitu sebagian besar komputer sudah terpasang antivirus tambahan, gangguan jaringan terjadi maksimal tiga kali dalam satu bulan dan password diperbarui setiap enam bulan sekali, sebagian besar komputer sudah terdapat password untuk mengaskes komputer, melakukan back-up data rutin setiap satu bulan sekali, ruangan server terpasang CCTV, dan penanganan apabila terjadi gangguan jaringan akan diperbaiki 1x24 jam. Dari standart tersebut maka dapat disimpulkan bahwa standar keamanan sistem informasi Tsabita Cake sebesar 70\%, akan tetapi dari hasil wawancara yang sudah dilakukan PT. Tsabita Cake saat ini sedang berada pada level 2 dan target yang ingiin dicapai adalah target 3 sesuai standar dari PT. Tsabita Cake.

Habiba, et., al [Evaluasi Tata Kelola Keamanan Sistem Informasi Menggunakan Framework Cobit 5 pada PT. Tsabita Cake 


\section{Analisis dan Pembahasan}

Berdasarkan hasil kuesioner dan wawancara yang telah dilakukan pada narasumber di bidang IT dan bidang persandian dan keamanan informasi tentang keamanan sistem informasi pada Tsabita Cake maka selanjutnya dilakukan penjelasan setiap level atribut. Berikut penjelasannya:

a. Level 0 (Incomplete Process)

Kriteria pada level ini mengenai kesadaran dan pengelolaan terhadap keamanan teknologi informasi pada Tsabita Cake, hasil yang dicapai pada level ini mendapatkan $69.16 \%$ dengan status Largely Achieved. Hal tersebut menujukan bahwa Tsabita Cake mengetahui pentingnya proses keamanan teknologi dan sistem informasi dalam pelaksanaan TI serta mendukung proses bisnis yang ada [9].

b. Level 1

Kriteria pada level ini mengenai tujuan yang sudah dicapai dan penerapan proses keamanan sistem informasi pada Tsabita Cake, hasil yang dicapai pada level ini mendapatkan 75\% dengan status Largely Achieved. Hal tersebut menujukan bahwa Tsabita Cake mengetahui pentingnya penerapan proses kemanan teknologi informasi

c. Level 2

Kriteria pada level ini membahas tentang bagaimana proses keamanan teknologi informasi pada Tsabita Cake telah mencapai tujuannya dan telah menerapkan kegiatan diataranya proses perbaikan, penyesuaian dan perencanaan kearah yang lebih baik. Pada level ini terdapat dua atribut yakni Perfomance Management menjelaskan tentang pengukuran performa dari proses keamanan sistem sistem informasi yang menghasilkan $72 \%$ dengan status Largely Achieved yang berarti proses keamanan saat ini belum dikelola dengan cukup baik dan Work Product Management menjelaskan tentang pengukuran hasil dari proses yang dikelola menghasilkan $77.5 \%$ dengan status Largely Achieved yang berarti bahwa proses keamanan informasi yang dilakukan sudah cukup baik akan tetapi dokumentasi dan hasil laporan kerja dari proses keamanan sistem informasi belum dikelola dengan baik. Rata-rata yang didapatkan pada level 2 ini dengan dua atribut tersebut sebesar $74.75 \%$, hal ini menunjukan bahwa proses kamanan sistem informasi belum dilaksanakan secara maksimal.

d. Level 3

Kriteria pada level ini membahas tentang seberapa jauh penilaian peforma proses keamanan sistem informasi pada Tsabita Cake, level ini memiliki dua atribut penilaian yakni Process Definition mengenai seberapa jauh pengukuran proses standar yang dikelola menghasilkan $67.67 \%$ dengan status Largely Achieved yang berarti bahwa pengelolaan proses keamanan sistem informasi hanya mencapai sebagian dan atribut Process Deployment menjelaskan tentang pengelolaan standar untuk mendukung proses yang telah berjalan menghasilkan $76.94 \%$ dengan status Largely Achieved yang berarti bahwa proses keamanan sistem informasi yang dikerjakan sudah sesuai dengan standar tetapi hanya mencapai sebagian. Rata-rata yang didapatkan pada level 3 ini dengan dua atribut tersebut sebesar $72.30 \%$ dengan status Largely Achieved, hal ini menunjukan bahwa proses keamanan sistem informasi sudah tercapai sebagian akan tetapi perencanaannya belum dikelola dengan cukup baik.

e. Level 4

Kriteria pada level ini membahas tentang bagaimana Tsabita Cake mengelola proses keamanan sistem informasi yang sedang berjalan dan sesuai dengan batasan yang sudah ditentukan untuk mencapai hasil yang diharapkan, level ini memiliki dua atribut yakni Process Measurement membahas tentang seberapa jauh hasil dari pengukuran yang dipakai dalam mematikan performa keamanan sistem informasi menghasilkan $69.58 \%$ dengan status Largely Achieved yang berarti bahwa pengukuran terhadap proses keamanan sistem informasi belum terpenuhi dan harus dilakukan perbaikan agar cepat baik dan atribut Process Control membahas 
tentang seberapa jauh proses kemanan sistem informasi dapat menjaga konsistensi dalam menjalankan proses dan memprediksi batasan yang sudah ditetapkan menghasilkan $72 \%$ dengan status Largely Achieved yang berarti bahwa proses kontrol keamanan sistem informasi terhadap performa dan pengelolaan hasil kontrol belum dilakukan dengan cukup baik. Rata-rata yang didapatkan pada level 4 ini dengan dua atribut tersebut sebesar $70.79 \%$ dengan status Largely Achieved, hal ini menunjukan bahwa penerapan proses kemanan sistem informasi baru tercapai sebagaian dan belum bisa dilakukan prediksi terhadap pengukuran kontrol.

f. Level 5

Kriteria pada level ini membahas tentang pengelolaan proses keamanan sistem informasi Tsabita Cake yang sedang berjalan terus ditingkatkan untuk memenuhi sasaran bisnis saat ini dan relevan dengan tujuan bisnis yang ditetapkan, level ini memiliki dua atribut yakni Process Inovation membahas mengenai ukuran sejauh mana perubahan pada proses keamanan sistem informasi dengan melakukan identifikasi dari analisis penyebab umum dalam kinerja dan penyelidikan pendekatan inovatid untuk mendefinisikan proses keamanan sistem informasi menghasilkan 71.67\% dengan status Largely Achieved yang berarti bahwa dalam pengelolaan proses kemanan sistem informasi baru saja diterapkan dan atribut Process Optimisation membahas mengenai sejauh mana perubahan dari kinerja proses keamanan sistem informasi tersebut didefinisikan oleh manajemen dari hasil proses tersebut akan berdampak efektif untuk mencapai tujuan perbaikan proses yang relevan menghasilkan $75.55 \%$ dengan status Largely Achieved yang berarti bahwa proses kemanan sistem informasi telah tercapai sebagian dan perubahan proses yang dihasilkan cukup baik hanya saja pengelolaan yang kurang. Rata-rata yang didapatkan pada level 5 ini dengan dua atribut tersebut sebesar $73.61 \%$ dengan status Largely Achieved yang berarti bahwa peningkatan pengelolaan proses keamanan sistem informasi belum berhasil dilakukan, pada inovasi dan optimasi baru saja berjalan sebagian.

5. Analisis Kesenjangan (GAP Analaysis)

Berikut merupakan hasil perhitungan analisis kesenjangan yang menggambarkan kondisi dari proses keamanan sistem informasi PT. Tsabita Cake dan harapan untuk kedepannya. Target level kapabilitas Tsabita Cake berada pada level 3. Sedangkan level kapabilitas Tsabita Cake mengenai pengelolaan proses saat ini ada pada level 2. Maka target selanjutnya yang harus dipenuhi adalah level 3, berikut merupakan analisis kesenjangan (Gambar 5) :

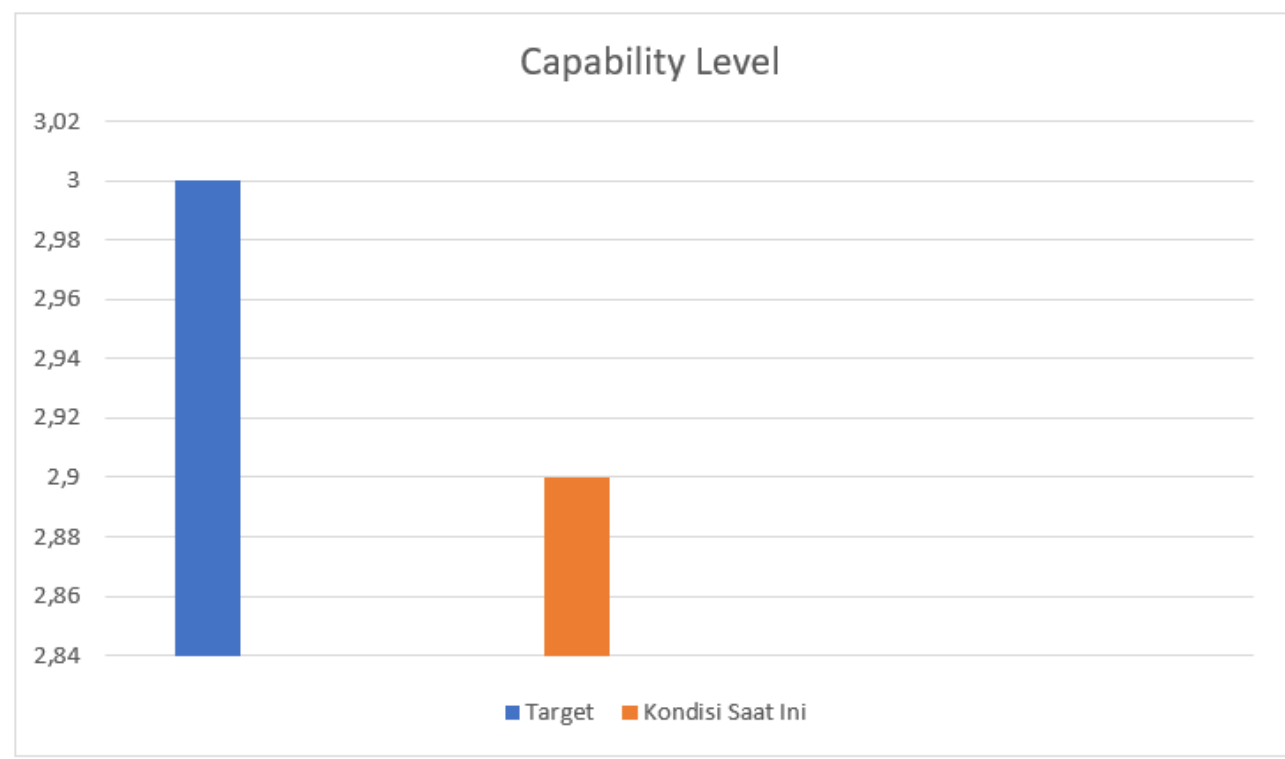

Gambar 5. Grafik Kesenjangan Kapabilitas

Habiba, et., al [Evaluasi Tata Kelola Keamanan Sistem Informasi Menggunakan Framework Cobit 5 pada PT. Tsabita Cake 
Grafik analisis kesenjangan diatas (Gambar 5) menunjukan bahwa nilai kesenjangan antara target tingkat kapabilitas dan tingkat kapabilitas saat ini hanya berbanding sebesar $0.1 \%$. Hasil dari pembahasan sebelumnya pencapaian level 2 yaitu sebesar $75 \%$ dengan status Largely Achieved, berdasarkan hasil tesebut maka dapat dilakukan analisa untuk memperbaiki kriteria pemenuhan pada setiap proes atribut level 1 dan level 2 agar mencapai Fully Achieved dengan hasil diatas $85 \%$ sesuai dengan tabel 5 . Berikut merupakan turunan kesenjangan yang dicapai pada setiap proses:

Tabel 5. Analisis Kesenjangan Proses Atribut Level 1-3

\begin{tabular}{lccc}
\hline \multicolumn{1}{c}{ Atribut } & $\begin{array}{c}\text { Presentase Kondisi } \\
\text { Saat Ini }\end{array}$ & Presentase Target & GAP \\
\hline $\begin{array}{l}\text { PA 1.1 Process Perfomance } \\
\text { PA 2.1 }\end{array}$ & $75 \%$ & $85 \%$ & $10 \%$ \\
\hline $\begin{array}{l}\text { Perfomance Managemet } \\
\text { PA 2.2 }\end{array}$ & $72 \%$ & $85 \%$ & $13 \%$ \\
\hline $\begin{array}{l}\text { Pork Product Managemet } 3.1 \\
\text { Process Definition }\end{array}$ & $77.5 \%$ & $85 \%$ & $7.5 \%$ \\
\hline $\begin{array}{l}\text { PA 3.2 } \\
\text { Process Deployment }\end{array}$ & $76.67 \%$ & $85 \%$ & $17.33 \%$ \\
\hline
\end{tabular}

6. Rekomendasi Perbaikan

Berdasarkan perhitungan Capability Level dan GAP Analysis serta melihat wawancara yang dilakukan, maka terdapat rekomendasi yang diberikan untuk melakukan perbaikan secara bertahap pada proses atribut level 1 sampai level 3. Pada atribut level 1 Process Perfomance rekomendasi yang diberikan untuk mencapai target ialah membuat kebijakan baru mengenai penggunaan perangkat hardware untuk melindungi komputer dari serangan malware dan mewajibkan setiap staff memberi password pada komputer masing-masing dan diupdate secara berkala, dan membuat kebijakan mengenai pengelolaan keamanan teknologi informasi yang mencakup semua bidang dimana apabila terjadi gangguaan atau masalah bisa dikomunikasikan dengan baik dan segera dilakukan perbaikan.

Pada atribut level 2.1 Perfomance Management rekomendasi yang diberikan untuk mencapai target ialah membuat dokumen yang berisi tentang penjabaran secara rinci kegiatan proses keamanan sistem informasi yang dilakukan dan menjalin komunikasi dengan pemangku kepentingan, dan membuat kebijakan mengenai beberapa hal yang boleh dan tidak boleh dilakukan apabila terjadi insiden dalam proses keamanan sistem informasi yang diluar rencana dan membuat beberapa opsi yang harus dilakukan untuk situasi tertentu, sedangkan pada atribut level 2.2 Work Product Management rekomendasi yang diberikan untuk mencapai target ialah membuat peraturan mengenai pelaporan hasil kerja dalam pencapaian proses keamanan sistem informasi dengan mewajibkan untuk mencantumkan sumber dengan tujuan menghindari apabila ada penyangkalan terhadap informasi yang dilaporkan, dan membuat kebijakan mengenai pengarsipan laporan hasil kerja yang dilakukan secara rutin dan stabil dalam jangka waktu tertentu agar saat terjadi masalah atau gangguan data, data yang diperlukan oleh stakeholder sudah tersedia dengan rapi pada arsip laporan kerja.

Pada atribut level 3.1 Process Definition rekomendasi yang diberikan untuk mencapai target ialah membuat SOP keamanan sistem informasi yang jelas dan rinci, SOP tersebut berisi 
tentang semua rangkaian kegiatan yang berhubungan dengan kemanan sistem informasi, dan membuat dokumen kebijakan yang lengkap dan detail mengenai infrastruktur TI yang dibutuhkan dan catatan mengenai penggunaan infrastruktur TI tersebut untuk mendukung proses perlindungan terhadap aset informasi. Pada atribut level 3.2 Process Deployment rekomendasi yang diberikan untuk mencapai target ialah membuat SOP rekrutmen SDM yang berisi tentang kewajiban merekrut SDM yang memiliki kemampuan dan basis pendidikan yang relevan dengan kegiatan keamanan sistem informasi, dan membuat kebijakan mengenai pengelolaan data proses keamanan sistem informasi dengan mengumpulkan data dan kemudian diserahkan kepada pemangku kepentingan untuk dapat dianalisis dan bisa digunakan dalam mengambil keputusan.

\section{KESIMPULAN DAN SARAN}

\subsection{Kesimpulan}

Berdasarkan hasil dan pembahasan yang telah dilakukan, maka kesimpulan penelitian pada Tsabita Cake tentang proses keamanan informasi yakni Tingkat kapabilitas proses keamanan sistem informasi pada Tsabita Cake saat ini yaitu berada pada level 2 dengan status Largely Achieved dengan rata-rata $75 \%$ atau setara dengan 2,90. Tingkat kesenjangan yang dihasilkan adalah sebesar 0,1. Dengan begitu maka keamanan sistem informasi pada Tsabita Cake sudah cukup baik. Setelah mengetahui hasil evaluasi yang menyatakan bahwa keamanan sistem informasi Tsabita Cake saat ini berada pada level 2, perusahaan terkait ingin meningkatkan nilai Capability Level agar tercapai target yaitu level 3 .

\subsection{Saran}

Saran yang diberikan untuk penelitian selanjutnya yaitu diharapkan menggunakan domain Align, Plan and Organise (APO) atau Evaluate, Direct, Monitor (EDM) yang dimiliki oleh framework COBIT 5 untuk mengevaluasi dan menganalisa tata kelola teknologi informasi secara keseluruhan pada PT. Tsabita Cake

\section{DAFTAR PUSTAKA}

[1] Ali, R. M., \& Agushinta, D. 2019, Evaluasi Tata Kelola Teknologi Informasi pada Sistem Informasi Akademik Fakultas Teknik Universitas Khairun Ternate Menggunakan Framework Cobit 5, Volume 6, No. 2, Jurnal Manajemen Informatika.

[2] Anas, S., Wahyu Winarno, W., \& Al Fatta, H, 2017, Evaluasi Tata Kelola Teknologi Informasi Akademik STMIK Dipanegara Makassar, Volume 4 No. 1, pages 28-33, Jurnal PPKM I.

[3] Irvan Salegar. 2018, Analisis Tatakelola Sistem Informasi pada PT. Duta Kartika Agro Lestari Menggunakan Cobit 4. 1 (Studi Kasus: PT. Duta Kartika Agro Lestari), Volume 2, No. 1, pages 33-42. Jurnal AKSI (Akuntansi dan Sistem Informasi).

[4] Ohnoi, R., Ohno, T., Takahashi, H., Kuroda, Y., Oss, T. E. L., Oss, F. a X., \& Hospita, G. 2006, Analisis Tingkat Kematangan Tata Kelola TI Pada Sistem Informasi Akademik Menggunakan Cobit 5 (Studi Kasus: Sistem Informasi Akademik di STT Terpadu Nurul Fikri), Volume 01, No. 1, hlm. 125-134. 
[5] Salegar, I., \& Rizal, S. 2020, Evaluasi Kematangan Tata Kelola Sistem Informasi Akademik Perguruan Tinggi Menggunakan COBIT 5.0, pages 87-90.

[6] Wahab, I. H. A., \& Arief, A. 2016, An Integrative Framework of COBIT and TOGAF for Designing IT Governance in Local Government, pages 36-40.

[7] Wahyuni, R. 2018, Evaluasi Untuk Perbaikan Sistem Informasi Akademik Menggunakan Cobit 5 Di STMIK Hang Tuah Pekanbaru, Jurnal Ilmu Komputer, Volume 6, No. 2, hlm 91-96

[8] Sugiyono. 2013, Metode Penelitian Kuantitatif, Kualitatif dan R\&D, Alfabeta, Bandung.

[9] Turban, Leidner, McLean, and Wetherbe. 2008, Information Technology for Management, 6th ed.: John Wiley \& Sons (Asis) Pte Ltd.

[10] Wu Fang, Mahajan Vijay \& Sridhar Balasubramanian. 2003, An Analysis of E-Business Adoption and its Impact on Business Performance", Journal of The Academy of Marketing Science, Volume 31, No. 4, pages 425-447 